\title{
Correction to: Daratumumab: A Review in Relapsed and/or Refractory Multiple Myeloma
}

\author{
Hannah A. Blair ${ }^{1}$
}

Published online: 24 January 2018

(C) Springer International Publishing AG, part of Springer Nature 2018

\section{Correction to: Drugs (2017) 77:2013-2024}

https://doi.org/10.1007/s40265-017-0837-7

The author has alerted us to the following error in Sect. 4.2.2.1, and the following correction should be noted:

Page 2019, Sect. 4.2.2.1, paragraph 1, lines 6-10: the following sentence, which previously read:

"After a median follow-up of 24.5 months, daratumumab plus lenalidomide and dexamethasone was still associated with significantly $(p<0.0001)$ prolonged median PFS relative to lenalidomide plus dexamethasone (not reached vs. 17.5 months; HR 0.41; 95\% CI 0.31-0.53)".

should read:

"After a median follow-up of 25.4 months, daratumumab plus lenalidomide and dexamethasone was still associated with significantly $(p<0.0001)$ prolonged median PFS relative to lenalidomide plus dexamethasone (not reached vs. 17.5 months; HR 0.41 ; 95\% CI $0.31-0.53)$ ".

The original article can be found online at https://doi.org/10.1007/ s40265-017-0837-7.

Hannah A. Blair

demail@springer.com

1 Springer, Private Bag 65901, Mairangi Bay, 0754 Auckland, New Zealand 